\title{
RISK ASSESSMENT TERHADAP PENGOPERASIAN AUXILIARY STEAM BOILER PADA KAPAL TANKER PERTAMINA MT. PELITA
}

\author{
$\operatorname{Ardiansyah}^{\mathrm{a}^{*}}$ Dirhamsyah $^{\mathrm{b}}$, Yohan Wibisono ${ }^{\mathrm{c}}$ \\ ${ }^{a, b, c}$ Dosen Program Studi Teknika, Politeknik Pelayaran Surabaya \\ *Ardi Ardi08@yahoo.com
}

\begin{abstract}
ABSTRAK
Auxiliary steam boiler adalah sebuah pesawat bantu dalam sistem permesinan kapal yang berfungsi sebagai pesawat penunjang untuk kerja dari mesin penggerak utama kapal dan operasi kapal secara berkesinambungan secara terus menerus dengan aman dan selamat. Uap yang dihasilkan digunakan sebagai pemanas, baik pemanas bahan bakar, minyak lumas, minyak kotor dan keperluan akomodasi, pemanas muatan kapal dan kegagalan auxiliary steam boiler dapat mengancam keselamatan operator (masinis/oiler kapal) maupun seluruh Anak Buah Kapal (ABK) diatas kapal. Teknik yang digunakan dalam mengidentifikasi risiko adalah penilaian berdasarkan dokumen dan wawancara, juga pengidentifikasian risiko dan penilaian risiko pada auxiliary steam boiler dengan menggunakan metode Hazard and Operability Study (HAZOP). Dari pengamatan yang dilakukan selama di atas kapal ditemukan adanya Jilatan api yang tidak konsisten sehingga menyebabkan sistem penyalaan bermasalah, kurangnya pemahaman terhadap pengoperasian boiler, kurangnya kesadaran terhadap bahaya dari auxiliary steam boiler serta kurangnya pemahaman akan standar keselamatan kerja bagi awak kamar mesin. Dengan menggunakan teori HAZOP dapat diidentifikasi masalah-masalah dari penyebab kegagalan dalam sistem penyalaan pada ruang pembakaran yaitu kurangnya pemahaman terhadap pengoperasian boiler dengan terkait langkah-langkah prosedur pengoperasian auxiliary steam boiler berdasarkan intructional manual book, kurangnya pemahaman crew terhadap standar keselamatan kerja auxiliary steam boiler dengan memberikan langkah-langkah standar keselamatan kerja auxiliary steam boiler secara konstruksi para awak kapal dan awak kapal wajib mengetahui secara pasti hal-hal mengenai pengetahuan teknis praktis bejana tekan.
\end{abstract}

Kata kunci: risk assessment, auxiliary steam boiler, kapal tanker

\section{PENDAHULUAN}

Pertamina sebagai sebuah perusahaan minyak negara yang memiliki banyak kapal tanker diantaranya kapal MT. Pelita, kapal tersebut membawa muatan bahan bakar yang akan didistribusikan ke seluruh wilayah Indonesia terutama wilayahwilayah bagian timur Indonesia. pada umumnya di kapal-kapal tangker untuk menunjang kelancaran pelayanan dan pelayaran dibutuhkan pesawat-pesawat bantu diantaranya adalah auxiliary boiler di mana berfungsi sebagai penghasil uap panas yang akan di gunakan untuk memanaskan muatan, memompa keluar muatan, memanaskan bahan bakar, sebagai pengontrol suhu udara bila kita berlayar di daerah dingin dan di gunakan untuk keperluan lainnya. Boiler atau boleh juga kita sebut juga dengan ketel uap adalah sebuah bejana tertutup yang dapat membentuk uap dengan tekanan lebih besar dari sari atmosfer dengan jalan memanaskan air boiler yang berada didalamnya dengan gas-gas panas dari hasil pembakaran bahan bakar. Namun dalam kegiatan operasional pada umumnya di atas kapal secara rutinitas pengawasan dan pemeliharaan terhadap boiler tersebut 
kurang maksimal dilakukan, sehingga peneliti merasa perlu melakukan suatu analisa resiko yang akan dihadapi oleh para operator boiler kapal sebagai salah satu metode dalam pemeliharaan dan bagaimana cara mengurangi risiko atau menghindari risiko bahayanya ketika terjadi kendala dalam operasional boiler.

Steam boiler didesain mengikuti peraturan keselamatan kerja baik yang dilakukan oleh pemerintah maupun oleh badan Biro Klasifikasi Indonesia (BKI), sehingga boiler aman untuk dioperasikan di atas kapal. Boiler dilengkapi dengan peralatan safety device sehingga terhindar dari bahaya kebakaran maupun peledakan.

Pada saat pengoperasian boiler diperlukan prosedur yang aman sesuai petunjuk manual book. Begitu juga menyangkut perawatan atau maintenanace boiler harus dilakukan dengan baik sesuai dengan jadwal perawatan boiler di kapal. Ada kalanya pengoperasian dan perawatan boiler dilakukan tidak dengan benar, hal ini terjadi akibat ketidaktahuan atau kurang pemahaman operator dalam penanganan boiler. Tujuan penelitian ini yaitu mengetahui kendala yang dihadapi dalam pengoperasian kendala yang dihadapi dalam pengoperasian auxiliary sistem boiler serta penanggulangan terjadinya resiko kegagalan dalam pengoperasian auxiliary sistem boiler.

\section{Steam Boiler}

Sebuah steam boiler harus cukup kuat supaya dapat bekerja dengan aman pada tekanan tertentu dan karenanya juga harus diperlengkapi dengan alat-alat/pesawatpesawat keamanan yang dikenal dengan appendasi steam boiler. Sebuah Steam boiler harus memenuhi persyaratanpersyaratan sebagai berikut:

1. Dalam waktu tertentu harus dapat menghasilkan uap dengan berat tertentu dan tekanan lebih besar dari 1 (ATM) Atmosfer;

2. Uap yang dihasilkan harus dengan kadar air yang sedikit mungkin;
3. Kalau dipakai alat pemanas lanjut, maka pada pernakaian uap yang tidak teratur suhu uap tidak boleh berubah banyak dan harus dapat diatur dengan mudah.

\section{Klasifikasi Steam boiler}

Secara garis besar pembagian-pembagian steam boiler yaitu :

1. Pembagian menurut undang-undang uap Karena tempat penggunaannya berbedabeda, maka menurut Undang-Undang Uap pasal 9, Steam boiler dibagi menjadi tiga kelompok yaitu :

a. Steam boiler tetap atau Steam boiler darat, yaitu steam boiler yang dipakai di darat seperti pabrik-pabrik, PLTU dan lain-lain yang mempunyai pondasi yang tetap.

b. Steam boiler kapal, yaitu steam boiler yang dipakai di kapal. Di sini perlengkapan alat-alat keselamatan steam boiler biasanya mempunyai konstruksi yang sedikit berbeda dengan steam boiler lainnya, mengingat keadaan kapal-kapal yang selalu oleng selama berlayar.

c. Steam boiler yang dapat bergerak, yaitu steam boiler yang tidak termasuk dalam kedua golongan steam boiler tersebut di atas, seperti steam boiler kereta api, steam boiler tiang pancang dan lain-lain.

2. Pembagian menurut konstruksinya

Dilihat dari zat yang mengalir di dalam pipanya, steam boiler dibagi menjadi tiga golongan yaitu :

a. Steam boiler Pipa Api

Pada steam boiler ini gas-gas panas mengalir di dalam pipa, sedangkan air yang dipanasi berada di luar pipa. Contohnya adalah assessment Schots dan assessment Cochran .

b. Steam boiler Pipa Air

Pada steam boiler ini yang mengalir di dalam pipa adalah air steam boiler, sedangkan gas-gas pemanasnya berada di luar pipa. Pada masa kini steam boiler pipa air ini lebih pesat perkembangannya. Contohnya adalah 
assessment Babcock dan Wilcox, Assessment Foster Wheeler dan Steam boiler Yarrow.

c. Steam boiler Gabungan Pipa Api dan Pipa Air

Pada steam boiler ini terdapat dua macam jenis pipa : yaitu pipa api dan pipa air. Konstruksinya pada umumnya seperti Assessment Schots. Dan nampaknya dibuatnya steam boiler ini adalah untuk memperbaiki kekurangan yang terdapat pada assessment Schots, seperti kurang baiknya sirkulasi air di dalam steam boiler. Contohnya adalah Assessment Werkspoor, Assessment Howden and Johnson dan assessment Proudhon and Capus, dan lain sebagainya.

3. Pembagian menurut fungsinya di kapal Pada suatu instalasi uap, mutlak harus ada suatu pesawat yang akan mempergunakan uap hasil dari steam boiler. Penggunaan uap di kapal tergantung juga pada jenis mesin penggerak dari kapal, apakah kapal uap ataukah kapal motor. Pada kapal-kapal motor penggunaan uap sudah barang tentu hanya untuk pesawat bantu saja. Sedangkan pada kapal-kapal uap, penggunaan utama dari uap adalah untuk menggerekkan mesin induk, sedangkan penggunaan lain adalah untuk keperluan pesawat-pesawat bantu. Maka dari itu menurut fungsinya di kapal, steam boiler dibagi menjadi dua golongan yaitu:

a. Steam boiler Induk

Yaitu steam boiler yang menghasilkan uap yang dipergunakan untuk menggerakkan mesih induk. Pada masa kini steam boiler yang dipergunakan sebagai steam boiler induk pada umumnya steam boiler pipa air, seperti Foster Wheeler, Babcock dan Wilcok dan lain-lain.

b. Steam boiler Bantu

Yaitu steam boiler yang menghasilkan uap yang dipergunakan untuk keperluan pesawat bantu, seperti pompa-pompa, pemanas dan lain-lain. Jenis-jenis steam boiler yang. Biasanya dipergunakan sebagai steam boiler bantu misalnya Steam boiler Schots, Steam boiler Cochran dan lain-lain.

Pada kapal Motor Besar pada umumnya mempunyai steam boiler bantu. Manfaat steam boiler bantu adalah untuk pemanasan di kapal, seperti pemanas ruangan, dapur, bahan bakar serta untuk menggerakkan pesawat-pesawat bantu. Steam boiler semacam ini pada umumnya selain diopak dengan bahan bakar minyak, biasanya juga dikombinasi dengan memanfaatkan panas dari gas buang yang keluar dari motor induk.

\section{Risiko}

Risiko didiskripsikan sebagai suatu kemungkinan dari suatu kejadian yang tidak diinginkan sehingga mempengaruhi pencapaian tujuan suatu aktivitas atau obyek. Risiko tersebut diukur dalam consequences dan likelihood. Beberapa contoh konsekuensi yang dapat terjadi, yaitu :

1. Kegagalan dalam meraih kesempatan;

2. Kerusakan dari peralatan atau mesinmesin produksi;

3. Kebakaran dan kecelakaan kerja;

4. Kerusakan dari peralatan kantor atau sistem komputer;

5. Pelanggaran terhadap keamanan.

Risiko memiliki beberapa jenis, jenis risiko tersebut antara lain :

1. Operational risk adalah kejadian risiko yang berhubungan dengan operasi organisasi perusahaan, mencakup risiko yang berhubungan dengan sistem organisasi, proses kerja, teknologi dan sumber daya manusia.

2. Financial risk adalah risiko yang berdampak pada kinerja keuangan perusahaan, seperti kejadian risiko akibat dari tingkat fluktuasi mata uang, tingkat suku bunga, teramsuk risiko pembelian kredit, likuidasi dan pasar. 
3. Hazard risiko adalah risiko yang berhubungan dengan kecelakaan fisik, seperti kejadian risiko sebagai akibat bencana alam, berbagai kejadian/kerusakan yang menimpa harta perusahaan, dan adanya ancaman perusakan.

4. Strategic risk mencakup kejadian risiko yang berhubungan dengan strategis perusahaan, politik ekonomi, peraturan dan perundangan, pasar bebas, risiko yang berkaitan dengan reputasi perusahaan, kepemimpinan, dan termasuk perubahan keinginan perusahaan. (Veritas, N,Det 92001)

\section{Risk Assessment}

Menurut pendapat Veritas, N.Det (2001) Risk assessment adalah aplikasi khusus sama dengan bantuan untuk proses membuat keputusan. Sama seperti kebebasan yang dievaluasi, risk assessment adalah kritik untuk analisa level dari risiko yang diperkenalkan dengan macam-macam pilihan. Analisa dapat ditujukan pada risiko-risiko keuangan, risiko-risiko kesehatan, risiko-risiko keamanan, risikorisiko lingkungan dan risiko-risiko lainnya. Analisa yang sesuai atau cocok untuk risiko-risiko ini akan memberikan informasi dimana merupakan kritik yang baik untuk membuat keputusan, dan akan mengklarifikasi keputusan tersebut.

Risk assessment bukan merupakani bidang yang baru. Teknik risk assessment yang resmi merupakan dasar dari industri asuransi. Seperti halnya umur perusahaan yang diprogram dan bisnis-bisnis yang diawali dengan investasi modal besar, risk assessment menjadi bisnis yang diperlukan untuk memahami risiko yang dihubungkan dengan menjalankan perusaham dan untuk dapat mengatur risiko menggunakan ukuran control dan asuransi. Untuk industri asuransi agar dapat bertahan, risk assessment menjadi penting sekali untuk dapat menghitung risiko yang dihubungkan dengan kegiatan yang diasuransikan.
Seperti perusahaan-perusahaan menjadi lebih lazim dengan teknik risk assessment, teknik ini diaplikasikan lebih banyak untuk proses mernbuat keputusan, terjadi ketika tidak ada persyaratan yang berkaitan dengan aturan yang harus dikerjakan. Untuk mengakses data dan teknik menganalisa untuk memperbaiki, risk assessment akan menjadi lebih mudah untuk membentuk dan aplikasi-aplikasi lainnya, keduanya perintah dan sukarela, dapat diperkirakan. Dengan risk assessment, sebuah perusahaan akan dapat mengontrol prioritas dan frekuensi program inspeksi yang dilakukan, sehingga berdampak pada meningkatnya waktu operasi atau dengan kata lain dapat mengurangi waktu tidak pakai dari sebuah perusahaan atau unit kerja.

Risk assessment merupakan proses keseluruhan dari analisa risiko dan evaluasi risiko serta sebuah pengujian yang hati-hati dari apa yang ada dipekerjaan kita yang dapat menyebabkan bahaya terhadap orang, sehingga kita dapat menimbang apakah kita telah mengambil langkah pencegahan atau sesuatu yang seharusnya dikerjakan untuk mencegah bahaya tersebut. Sedangkan tujuan utamanya adalah untuk meyakinkan bahwa tidak ada orang yang mendapat kecelakaan.

\section{Hazard and Operability Study (HAZOP)}

Menurut viana J. Anda. Handoko Lukman. Firmansyah C. Ardie (2007), Implementasi Metode Hazop (Hazard and Operability Study). Dalam proses identifikasi bahaya dan analisa resiko pada feedwater system di unit pembangkitan Paiton, PT. PJB. Pembelajaran HAZOP untuk mengidentifikasi masalah risiko dan pengoperasian. Konsepnya meliputi investigasi dari desain tujuan. Dalam proses mengidentifikasi masalah selama pembelajaran HAZOP, pemecahannya terekam sebagai bagian dari hasil HAZOP dan bagaimanapun juga, harus ada kepedulian untuk menghindari percobaan demi menemukan kenyataan, karena tujuan 
utama dari HAZOP adalah untuk mengidentifikasi masalah.

\section{Definisi dan Tujuan HAZOP}

The Hazard and Operability Study, dikenal sebagai HAZOP adalah standar teknik analisis bahaya yang digunakan dalam persiapan penetapan keamanan dalam sistem baru atau modifikasi untuk suatu keberadaan potensi bahaya atau masalah operabilitasnya. Studi HAZOP adalah pengujian yang teliti oleh group spesialis, dalam bagian sebuah sistem mengenai apakah yang akan terjadi jika komponen tersebut dioperasikan melebihi dari normal model desain komponen yang telah ada.

Tujuan penggunaan HAZOP adalah untuk meninjau suatu proses atau operasi pada suatu sistem secara sistematis, untuk menentukan apakah proses penyimpangan dapat mendorong kearah kejadian atau kecelakaan yang tidak diinginkan.

\section{Karakteristik HAZOP}

Sebagai suatu teknik yang digunakan untuk mempelajari kemungkinan penyimpangan dari operasi normal, HAZOP memiliki karakteristik sebagai berikut :

- Sistematik, menggunakan struktur atau susunan yang tinggi dengan mengandalkan pada guide words dan gagasan tim untuk melanjutkan dan memastikan safe guards sesuai atau tidak dengan tempat dan objek yang sedang diuji;

- Pengkhususan bentuk oleh berbagai macam disiplin ilmu yang dimiliki oleh anggota tim;

- Dapat digunakan untuk berbagai macam sistem atau prosedur;

- Penggunaanya lebih sebagai sistem pada teknik penafsiran bahaya;

- Perkiraan awal, sehingga mampu menghasilkan kualitas yang baik meskipun kuantitas adalah juga mempengaruhi.

HAZOP dapat digunakan secara bersamaan dalam proses identifikasi safety hazard dan juga pada sistem operasi secara berkelanjutan, khususnya pada fluida dan juga digunakan secara bersamaan untuk review prosedur serta rangkaian operasi

Teknik HAZOP merupakan teknik kualitatif yang mudah dipelajari yang teliti, sistematis, logis, dan menuntut untuk memperoleh hasil yang teliti. Keunggulan metode HAZOP diantaranya: mudah dipelajari, memacu kreatifitas dan membangkitkan ide-ide, sistematis, telah diterima secara luas sebagai salah satu metode untuk identifikasi bahaya, tidak hanya fokus pada masalah safety, karena merupakan identifikasi bahaya (Hazard) untuk pencegahan terjadinya kecelakaan serta operasi (Operability) yang berguna agar proses dapat berjalan lancar sehingga meningkatkan plant performance (Product quality, production rate, profit).

\section{Konsep HAZOP}

Istilah-istilah terminologi (key words) yang dipakai untuk mempermudah pelaksanaan HAZOP antara lain sebagai berikut:

- Deviation (Penyimpangan). Adalah kata kunci kombinasi yang sedang diterapkan. (merupakan gabungan dari guide words dan parameters).

- Cause (Penyebab). Adalah penyebab yang kemungkinan besar akan mengakibat kan terjadinya penyimpangan.

- Consequence (Akibat/konsekuensi). Dalam menentukan consequence tidak boleh melakukan batasan kerena hal tersebut bisa merugikan pelaksanaan penelitian.

- Safeguards (Usaha Perlindungan). Adanya perlengkapan pencegahan yang mencegah penyebab atau usaha perlindungan terhadap konsekuensi kerugian akan didokumentasikan pada kolom ini. Safeguards juga memberikan informasi pada operator tentang pemyimpangan yang terjadi dan juga untuk memperkecil akibat. 
- Action (Tindakan yang Dilakukan). Apabila suatu penyebab dipercaya akan mengakibatkan konsekuensi negatif, harus diputuskan tindakan-tindakan apa yang harus dilakukan.

- Node (Titik Studi). Merupakan pemisahan suatu unit proses menjadi beberapa bagian agar studi dapat dilakukan lebih terorganisir. Titik studi bertujuan untuk membantu dalam menguraikan dan mempelajari suatu bagian proses.

- Severity. Merupakan tingkat keparahan yang diperkirakan dapat terjadi.

- Likelihood. Adalah kemungkinan terjadinya consequence dengan sistem pengaman yang ada.

- Risk atau risiko merupakan kombinasi kemungkinan likelihood dan consequence.

\section{METODE PENELITIAN}

Penelitian yang dilakukan ini adalah termasuk ke dalam penelitian kualitatif deskriptif yaitu penelitian yang akan mengungkapkan kejadian atau fakta, keadaan, fenomena, variabel dan keadaan yang terjadi saat penelitian berlangsung dengan menyuguhkan apa yang sebenarnya terjadi.

1. Objek Penelitian

Yang menjadi objek di dalam kegiatan penelitian ini adalah sesuai dengan tujuan penelitian yang telah diuraikan yaitu meliputi:

a. Kendala operasional dalam auxiliary sistem boiler di Kapal MT. Pelita;

b. Penanggulangan jika terjadi kendala dalam pengoperasian auxiliary sistem boiler di kapal.

2. Lokasi Penelitian

Dalam penyusunan penelitian ini lokasinya dilakukan dan dilaksanakan di kapal MT. Pelita.
3. Waktu Penelitian

Penelitian dilakukan mulai dari tanggal

1 Maret 2018 sampai dengan 30 Desember 2018.

4. Metode Pengumpulan Data

Metode penelitian yang dilakukan adalah sebagai berikut:

a. Observasi

Pengumpulan data dilakukan dengan observasi, studi dokumentasi dari operasional steam boiler di kapal MT. Pelita.

b. Wawancara

Wawancara dilakukan dengan berkomunikasi langsung dengan pihak pihak terkait maupun yang ahli dalam hubungannya dengan steam boiler.

c. Dokumentasi

Dokumentasi dilakukan dengan menuliskan hasil penelitian ke dalam suatu laporan yang tersusun secara jelas berdasarkan data dan hasil pengamatan.

5. Analisa Data

Analisa data dilakukan dengan menuliskan dan menganalisis hasil kerja pengoperasian auxiliary steam boiler serta menguji kinerja komponen dan penggunaannya. 


\section{HASIL DAN PEMBAHASAN}

\section{Deskripsi Data}

Data-data boiler pada kapal MT. Pelita milik pertamina sebagai berikut :

\section{TECHNICAL DATA FOR WATER TUBE BOILER MODEL MISSION ${ }^{\mathrm{TM}}$ OC-TCI}

\section{GENERAL DATA}

Request No./Order No 104230-01-2,104230-02-2

Hull No./Nos $\mathrm{H} 2423, \mathrm{~h} 2424$

Maker AAlborg Indutries

\section{DIMENSION FOR BOILER UNIT}

$>$ Height to top of smoke oulet box. $.5,206 \mathrm{~mm}$

$>$ Diameter including insulation $.2,670 \mathrm{~mm}$

$>$ Weight of boiler unit exel.water. (*) $17.1 \mathrm{~mm}$

Weight of boiler unit encl.water..... 26.2 ton

3. WATER/STEAM PROCESS DATA

Steam Output, simultaneous operation $2.550 \mathrm{~kg} / \mathrm{h}$

Steam output, oil field section. $1.800 \mathrm{~kg} / \mathrm{h}$

$>$ Steam output, exhaust section $.750 \mathrm{~kg} / \mathrm{h}$

$>$ Working pressure $7.0 \mathrm{bar}$

$>$ Working temperature $1700 \mathrm{C}$

$>$ Max.allowable working pressure $9.0 \mathrm{bar}$

$>$ Feed water operation Modulating

$>$ Feed water temperature, layout $.800 \mathrm{C}$

\section{DATA FOR PRESSURE PART}

Boiler type Vertical, composite smoke/water tube boiler

Boiler model MISSIONTM OC-TCI

$>$ Test temperature 1,5 x Design Pressure bar

Protection of boiler body .silver (RAL9006)

$>$ Insulation thickness $75 \mathrm{~mm}$

$>$ Cladding type Trapez

$>$ Color of insulation plates Blue (RAL5002) 


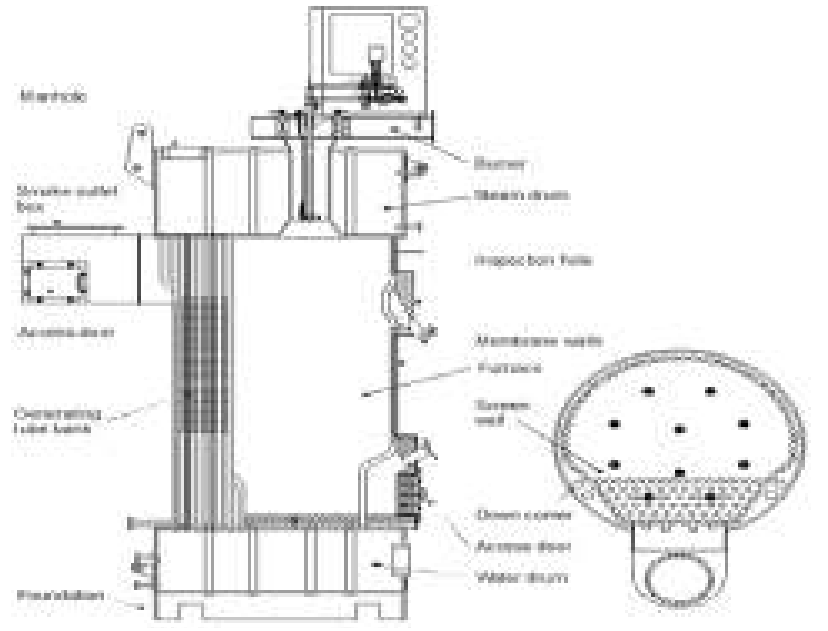

Gambar 1. Layout water tube boiler MT. Pelita

Dalam pembahasan ini langkah-langkah yang dilakukan oleh awak kapal terutama awak kamar mesin melakukan tindakan dalam proses penyalaan yang tidak sesuai dengan prosedur pengoperasian auxiliary steam boiler, oleh karena itu menjadi penyebab permasalahan dalam bahasan pokok permasalahan makalah ini. Dalam hal ini diambil salah satu dari identifikasi masalah ini. Dalam masalah ini penulis mengambil suatu teori dalam menentukan permasalahan ini yaitu menggunakan Hazard And Operability Study (HAZOP).

Prosedur keselatan kerja menjadi sangat penting dalam melakukan tindakan dalam operasional terhadap suatu pesawat apalagi pesawat tersebut diketahui memiliki risiko kecelakan yang sangat tinggi, oleh kerana itu ini menjadi pokok masalah kedua sehingga akan dibahas lebih lanjut berdasarkan analisa dan pembahasan di bawah ini:

\section{1) Sistem penyalaan bermasalah}

a. Jilatan api pertama kali tidak konsisten

Pada penyebab permasalahn ini diakibatkan kurang sampainya api ke dalam tube (lubang pipa) sehingga tidak tercapai penyalaan awal, hal ini bisa diidentifikasikan dengan menggunakan Hazop dan dikoreksi melalui Piping and Instrumented Diagram (P\&ID's) dari kapal MT.
Pelita yang bersangkutan dengan P\&ID's ditentukan 11 titik studi (study node) untuk mempermudah dan memfokuskan pengerjaan HAZOP. Pembuatan identifikasi Hazop berdasarkan study node yang telah ditentukan oleh tim Hazop, sehinga terdapat beberapa nilai kriteria likelihood, severity dan risk dan terdapat 11 (sebelas) titik studi dan nilai kriteria.

Setelah study node ditetapkan pengerjaan Hazop mulai dilaksanakan untuk dilakukan identifikasi potensi bahaya. Penilaian kategori severity dan likelihood pada identifikasi Hazop mengacu pada data kegagalan 15 Agustus 2016 beserta pengalaman operator dan pihak-pihak terkait/engineer pada kapal MT. Pelita.

\section{b. Kurangnya pemahaman terhadap pengoperasian boiler}

Ada beberapa faktor terjadinya sehingga awak kamar mesin belum sepenuhnya memahami tentang operasional auxiliary steam boiler antara lain :

1. Kurangnya pengalaman dalam pengoperasian auxiliary steam boiler; 
2. Tidak adanya petunjuk yang pasti sehingga terkadang awak kapal melakukan hanya berdasarkan pengalaman yang sedikit;

3. Tidak diberikannya petunjukpetunjuk pengoperasian atau Kepala Kamar Mesin kurang memberikan kepahaman yang berlanjut terhadap awak kamar mesin.

\section{2) Kurangnya pemahaman crew terhadap standar operasional auxiliary steam boiler}

a. Kurangnya kesadaran terhadap bahaya dari auxiliary steam boiler Dalam hal ini prosedur merupakan hal yang paling utama dalam rangka pelaksanaan pengoperasian auxiliary steam boiler, karena kurangnya kesadaran dalam pelaksanaan pengoperasian dapat berakibat fatal terhadap awak kapal terutama yang berhubungan langsung terhadap pesawat-pesawat yang ada di kamar mesin terutama auxiliary steam boiler, oleh karena itu perlu beberapa langkah dalam mengantisipasi dan menghindari penyebab kecelakaan kerja.

b. Kurangnya pemahaman crew terhadap standar keselamatan kerja auxiliary steam boiler

Dalam rangka pelaksanan kegiatan operasional di kamar mesin perlu dipandang suatu hal yang paling utama sehingga ada slogan mengatakan "safety first" hal ini bertujuan agar setiap kegiatan yang berhubungan terhadap resiko kecelakaan sebaiknya kita memikirkan apa saja yang dapat menimbulkan kecelakaan terhadap diri sendiri maupun lingkungan karena hal ini dapat mempengaruhi kinerja dari sebuah sumber daya manusia, di dalam standar keselamatan kerja boiler yang disebut dengan appendasi ketel, appendasi ketel terbagi 2 yaitu :

- Appendasi ketel yang berhubungan dengan uap

Peralatan apa saja yang terdapat pada auxiliary steam boiler yang berhubungan dengan uap diantaranya adalah katub keselamatan, manometer.

- Appendasi ketel yang berhubungan dengan air

Peralatan apa saja yang terdapat pada auxiliary steam boiler yang berhubungan dengan air antara lain adalah glass duga, feedwater pump.

\section{Pemecahan Masalah}

a. Jilatan api pertama kali tidak konsisten

Pemecahan masalah tersebut di atas adalah:

1) Dengan mengunakan metode pengukuran Hazop

Teori Hazop digunakan untuk mengidentifikasi masalah-masalah dari penyebab kegagalan dalam sistem penyalaan pada ruang pembakaran antara lain :

Lakukan identifikasi peralatan penyalaan ada ruang pembakaran Periksa apakah proses blowdown belum sempurna sehingga masih terdapat kandungan air sehingga titik bakar pada ruang pembakaran belum tercapai.

2) Syarat-syarat air ketel agar bekerja dengan baik adalah sebagai berikut :

a) Tidak boleh mengandung kekerasan sementara maupun kekerasan tetap;

b) Kadar SI O2 harus rendah (larut dengan uap bertekanan tinggi dan bahaya pengendapan / karat pada sudu-sudu turbin uap);

c) Kadar zat-zat lain yang terlarut harus ditahan rendah;

d) Menjaga supaya PH air ketel baik (antara $9.6 \mathrm{~s} / \mathrm{d} 11$ ); 
e) Tidak boleh adanya udara atau gas-gas lain terlarut dalam air ketel;

\section{b. Kurangnya pemahaman terhadap} pengoperasian boiler

Pemecahan masalahnya adalah sebagai berikut:

Melaksanakan langkah-langkah prosedur pengoperasian auxiliary steam boiler dengan benar

Prosedur pengoperasian auxiliary steam boiler harus berdasarkan intructional manual book yang terdapat pada auxiliary steam boiler manual book, adapun langkah-langkah proses penyalaan pada auxiliary steam boiler adalah sebagai berikut :

- Pemeriksaan pendahuluan

Tahap pemeriksaan pendahuluan ini sangat penting dilakukan karena untuk memastikan semua perangkat pendukung sistem berjalan dengan baik, ini termasuk kinerja safety device untuk sisi keamanannya.

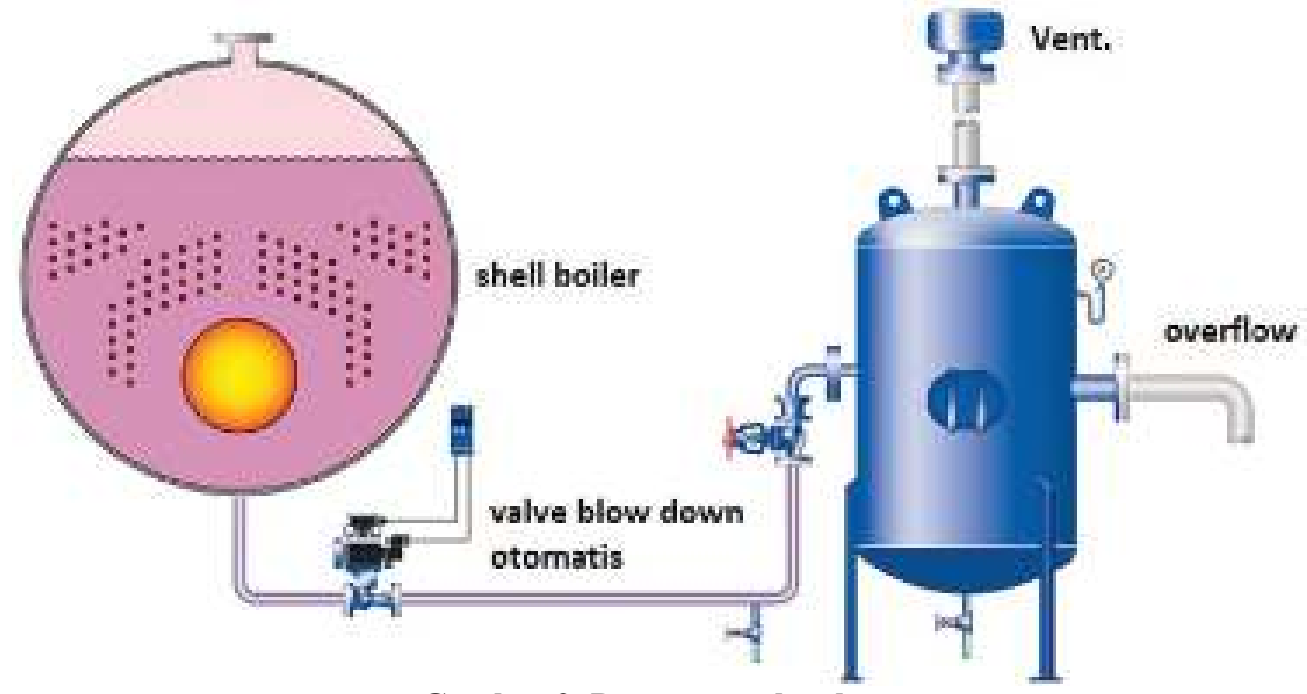

Gambar 2. Penampang ketel uap

c. Kurangnya kesadaran terhadap bahaya dari auxiliary steam boiler

Pemecahan masalah tersebut di atas adalah:

Memberikan pemahaman akan kesadaran dan prosedur keselamatan kerja a) Pemeriksaan katub-katub sebelum menjalankan, semua katub harus dalam keadaan tertutup, kecuali untuk katub superheater drain dan katub feedwater.

b) Pemeriksaan fisik, fisik disini lebih ke pemeriksaan mekanikal seperti pemeriksaan casing, bearing, van belt, baut-baut dan lain-lain.

c) Pemeriksaan level air memastikan level air di Gauge Glass sekitar level setengah, jika perlu dilakukan pembersihan pada glass dan kerangka agar pemantauan lanjutan lebih jelas.

d) Pemeriksaan Manometer (pressure gauge) Perlu pemantauan adakah tekanan awal atau tidak pada manometer. 
sehingga ruang kerja yang buruk sehingga tidak dapat melihat dengan jelas kondisi di sekitar auxiliary steam boiler. Diantara sebagai berikut:

1) Sepatu Pengaman/Selubung Kaki Sepatu pengaman harus dapat melindungi tenaga kerja terhadap kecelakaan-kecelakaan yang disebabkan oleh beban-beban berat yang menimpa kaki, pakupaku atau benda tajam lainnya yang mungkin terinjak, logam pijar, asam-asam, dan sebagainya.

2) Sarung Tangan

Sarung tangan digunakan untuk melindungi tangan dari tusukan dan sayatan benda tajam, terkena bahan kimia, benda panas dan sebagainya.

3) Topi Pengaman

Topi pengaman digunakan untuk melindungi kepala tenaga kerja dari benda-benda yang jatuh atau melayang. Topi yang digunakan harus keras dan kokoh, tetapi tetap ringan.

4) Perlindungan Telinga/Tutup Telinga

Jika perlu, telinga harus dilindungi dari suara bising yang dapat merusak pendengaran telinga.

5) Perlindungan Keseluruhan Tubuh

Tubuh juga harus dilindungi dari atmosfer yang berbahaya (uap beracun/debu radioaktif), dan sebagainya, seperti pakaian bertekanan udara yang dapat melindungi tubuh tenaga kerja pada saat bekerja.

\section{PENUTUP}

Berdasarkan hasil data yang telah terkumpul, pengolahan data dan analisa pada bab sebelumnya maka dapat disimpulkan beberapa hal sebagai berikut:

1. Jilatan api yang tidak konsisten maka menyebabkan sistem penyalaan bermasalah;
2. Karena kurang pemahaman terhadap pengoperasian boiler dapat menyebabkan sistem penyalaan bermasalah;

3. Karena kurangnya kesadaran terhadap bahaya dari auxiliary steam boiler mengakibatkan ledakan pada ruang pembakaran;

4. Karena kurangnya pemahaman akan standar keselamatan kerja bagi awak kamar mesin dapat memgakibatkan kecelakan pada awak kapal.

\section{Saran}

Beberapa saran yang dapat diberikan oleh peneliti berdasarkan hasil dari analisa yang telah dilakukan serta kesimpulan sebagai bahan pertimbangan perbaikan adalah sebagai berikut :

1. Untuk perusahaan agar dapat menggunakan Hazard and Operability study (Hazop) dapat menemukan secara cepat indikasi penyebab-penyebab dari kegagalan dalam operasi boiler;

2. Pihak manajemen perusahaan agar melaksanakan langkah-langkah dan prosedur peoperasian auxiliary steam boiler yang benar sehingga proses operasi auxiliary steam boiler menjadi baik;

3. Untuk pihak kapal terutama Kepala Kamar Mesin (KKM) agar memberikan pemahaman akan kesadaran akan bahaya terhadap operasi auxiliary steam boiler sehingga prosedur keselamatan kerja dapat dilaksanakan;

4. Untuk pihak manajemen perusahaan agar memberikan langkah-langkah standar keselamatan kerja auxiliary steam boiler.

\section{DAFTAR PUSTAKA}

\section{British Gas Plc Electrical power generation}

Family To Family Citations GB2253407A *1991-03-06199209-09 
Risk Assessment Terhadap Pengoperasian Auxiliary Steam Boiler Pada Kapal Tanker Pertamina Mt. Pelita

Ardiansyah $^{\mathrm{a}^{*}}$, Dirhamsyah ${ }^{\mathrm{b}}$, Yohan Wibisono ${ }^{\mathrm{c}}$

Bbc Brown Boveri \& CieCombined-cycle turbine power station with fluidisedbed coal gasification DE3642619A1 *1986-12-131988-

06-23

*Cited by examiner, + Cited by third party

Engineering, 1992; Guidelines for Hazard Evaluation Procedure., 1992) Aspects of understanding risk (American Institute of Chemical Hazard

Mannesmann AgMeans for vertical, discontinuous continuous casting of metals, particularly of steel DE3542518A1*1985-12-02198706-04

Metall gesell schaft Aktiengesell schaft Combined gas and steam turbine

process US4996836A *1986-04171991-03-05

Klaus Knizia Process for controlling the power output of a combination coalfired unit with integrated coal gasification and a coal power station operating according to the process US4896498A *1987-09191990-01-30

Kraftwerk Union Aktien gesell schaft Gas turbine and steam power-generating plant with integrated coal gasification plant US4631915A *1984-04-211986-1230

Switzer Jr George W Coal-fueled combined cycle power generating system US3986348A *1973-04-251976-1019 